\title{
Temporal and spatial variations in the Palmer Drought Severity Index over the past four centuries in arid, semiarid, and semihumid East Asia
}

\author{
HUA Ting ${ }^{*}$, WANG XunMing, ZHANG CaiXia \& LANG LiLi \\ Key Laboratory of Desert and Desertification, Cold and Arid Regions Environmental and Engineering Research Institute, Chinese Academy of \\ Sciences, Lanzhou 730000, China
}

Received January 26, 2013; accepted May 23, 2013; published online July 5, 2013

\begin{abstract}
Based on a database of 106 annually resolved tree-ring chronologies and 244 Palmer Drought Severity Index (PDSI) grid data, we attempted to reconstruct gridded spatial drought patterns in each year over the past four centuries in the arid, semiarid, and semihumid East Asia. The results showed that these regions mainly experienced drought events during the periods from AD 1601 to AD 1652, AD 1680 to AD 1718, AD 1779 to AD 1791, AD 1807 to AD 1824, AD 1846 to AD 1885, and AD 1961 to AD 1999. In the middle of the 16th century, severe droughts occurred mainly in North China; during the period from AD 1876 to AD 1878 , droughts occurred in most parts of northern China; and from the 1920s to 1940s, catastrophic drought events spread across almost all of northern China and Mongolia. These historical drought events caused severe ecological and environmental problems and substantially affected the development of human society. In these regions, temperature and summer monsoon precipitation are the main factors influencing drought events. In western areas, PDSI and temperature exhibit a close relationship, whereas in eastern areas, summer monsoon rainfall is the dominant factor influencing variations in PDSI.
\end{abstract}

East Asia, Palmer Drought Severity Index (PDSI), dendrochronology, drought event, forcing factors

Citation: Hua T, Wang X M, Zhang C X, et al. Temporal and spatial variations in the Palmer Drought Severity Index over the past four centuries in arid, semiarid, and semihumid East Asia. Chin Sci Bull, 2013, 58: 4143-4152, doi: 10.1007/s11434-013-5959-z

Although recently Sheffield et al. [1] suggested that drought events on a global scale actually showed little change over the past 60 years, it is widely believed that in arid, semiarid, and parts of semihumid regions, increasingly frequent and intensified drought events have been triggered by recent climate change [2-6]. The arid, semiarid, and semihumid East Asia (including northeastern China, part of North China, Mongolia, northwestern China, and part of central Asia) lies in the eastern portion of the Afro-Asian Arid Zone, and climate changes in this region have profound impacts on global climate system through the atmosphere general circulations. This region has high annual evaporation and low annual precipitation (mainly less than $450 \mathrm{~mm}$ with the humidity indices ranging from 0.05 to 0.65 ) with great inter-

*Corresponding author (email: hactgexin@1zb.ac.cn) annual variability [7], and the ecosystem is so fragile that frequent historical occurrences of drought events have caused tremendous problems such as desertification [8-10], agriculture failures [11], and sandstorms [12-14], as well as many other environmental issues [15]; therefore, reconstructing and researching historical spatiotemporal variations in drought events in this region is of great interest to researchers studying climatology, ecology, history, and environmental issues.

Because of the limited length and distributed range of observational records in arid, semiarid, and semihumid regions, many current studies of the history of drought in parts of Mongolia [16], northern China [8,17,18], and western East Asia [19,20] are based on evidences of tree-ring series [21-24], multi-indicators of lake sediments [19,25], and historical documentary records [26-28]. These studies 
either analyze the time series of dryness and wetness in a single location $[16,29,30]$ or use areal average/principal pattern to represent changes in dryness of the entire region [20], however, very few studies focus on a highly resolved spatiotemporal reconstruction and comprehensive integration of droughts. Therefore, in the present study, we used high-resolution tree-ring width chronologies and Palmer Drought Severity Index (PDSI) grid data to reconstruct the spatial patterns of drought and their evolutionary histories in the arid, semiarid, and semihumid regions of East Asia from AD 1601 to AD 1999 and to explore the possible influences of potential forcing factor on droughts.

\section{Data sources and reconstruction methods}

\subsection{PDSI grid data}

PDSI data were obtained from calculations of surface observational temperature and precipitation records to measure variations in soil moisture content that depend on surface water supply and demand. PDSI has been widely used to indicate meteorological and agricultural droughts [31,32], regional changes in dryness and wetness, and drought events in different historical periods. We used the $2.5^{\circ} \times 2.5^{\circ}$ spatial resolved PDSI grid data developed by Dai et al. [33], which cover the arid, semiarid, and semihumid regions of East Asia (Figure 1), as the main data sources. All of the 244 PDSI grid data span the common interval from AD 1953 to AD 1999. Since our study area includes some higher-latitude regions, where the monthly mean temperature in spring is very low, and the surface is always covered by snow and ice, which will affect the indications of PDSI because of their deficiencies in considering the effect of thawing snow and ice in spring and in representing the moisture condition of snowcapped surfaces [33]. In addition, since the precipitation in summer may play the most important role in crop and grass growths and the drought events occurred in this season had more impacts on ecological environments, we thus only used the PDSI series for the warm season (June to
August). Generally, the PDSI decreases as aridity intensifies and increases as climate gets wet. This index is a standardized measurement with a specific range from -10 to 10 ; therefore, PDSI values sampled from a wide spatial distribution could be compared to obtain a reliable spatial pattern in a given year as well as variations in these spatial patterns [34].

\subsection{Tree-ring dataset}

We developed a proxy network consisting of 150 annually resolved tree-ring width chronologies over arid, semiarid, and parts of semihumid East Asia from the International Tree-Ring Data Bank (ITRDB) (http://www.ncdc.noaa.gov/ paleo/treering.html) and other literature (Figure 1, Table S1); the details of detrending methods are provided in the source publications (Table S1). To reconstruct historical dryness (or PDSI) based only on variations in tree-ring chronologies, a close relationship should be established between tree-ring records and PDSI. Here, we performed one-tailed Pearson correlation tests for each tree-ring chronology and its nearest PDSI grid data to check the relationships between them. Chronologies with statistically significant positive correlations remained unchanged and were used directly in the study; those showing significant negative correlations were also acceptable because we could use the opposite series of the original chronologies to keep identical trends between the adjusted chronologies and PDSI in at least the common period. However, chronologies that failed to pass the correlation tests were eliminated from further calculations. We found that most chronologies were statistically significant at the 0.01 level but that some chronologies were significant at the 0.05 level (Table S2). Eventually, 106 chronologies that had passed the correlation significance tests were selected for the study.

The source tree-ring data were of varying time lengths, ranging from 130 to 800 years, and the number of chronologies declined backward in time (Figure 2). Therefore, during the reconstruction procedure, the time-varying tree-ring

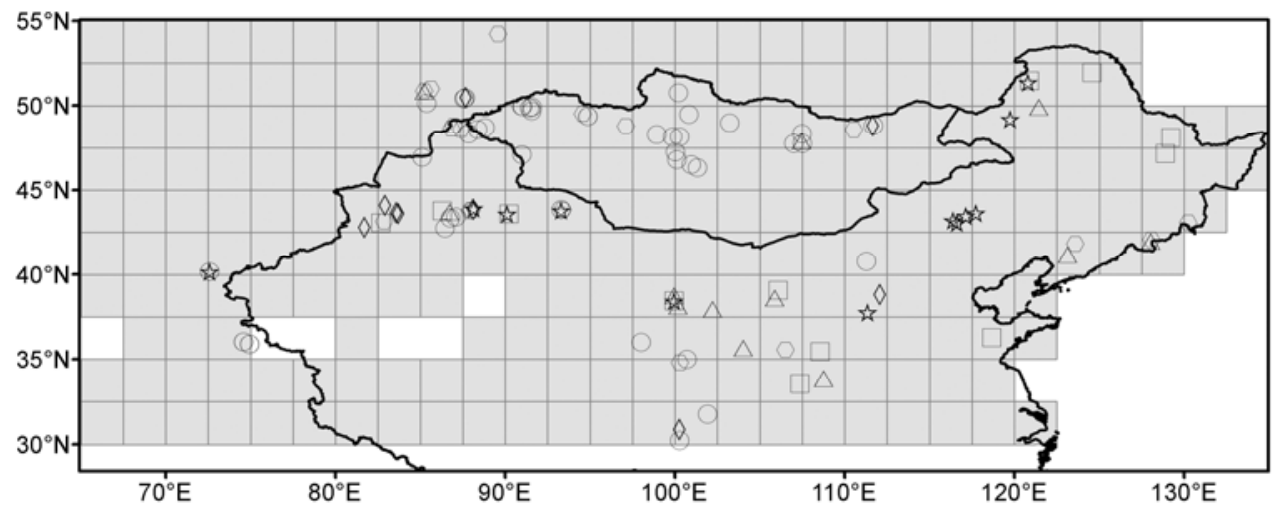

Figure 1 Arid, semiarid, and semihumid East Asia and distributions of PDSI grid data (gray squares). Locations of tree-ring chronologies are shown as symbols in terms of the year they extend back to (at a minimum) AD 1867 (stars), AD 1801 (triangles), AD 1750 (squares), AD 1697 (diamonds), AD 1651 (crosses), and AD 1601 (circles). 


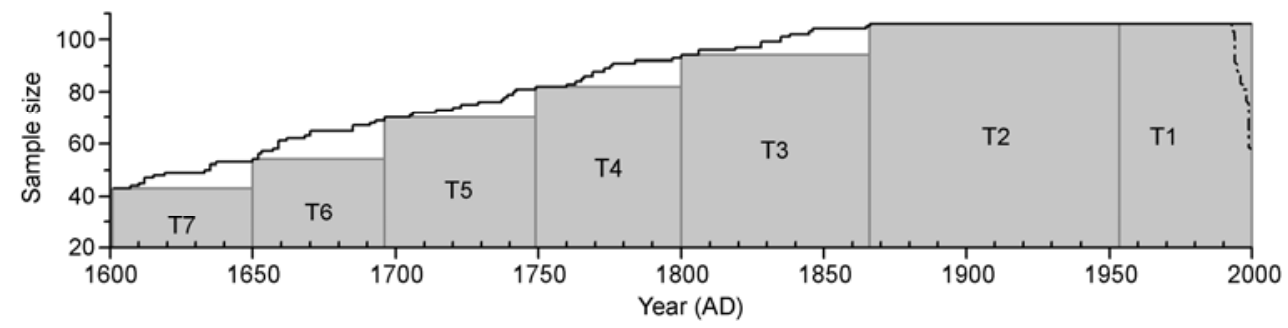

Figure 2 Variations in sample size of the true tree-ring chronologies (dashed line) and extended chronologies in the reconstruction procedure (solid line) and the seven reconstruction intervals ( $T 1$ to $T 7$, blue blocks; widths and heights of the blocks indicate time spans and number of chronologies used in each reconstruction interval, respectively).

dataset was divided into seven reconstruction intervals in terms of the number of ring-width chronologies available in each year. Within an interval, chronologies that their time span exceeded the common span were removed the extra part; consequently, the time spans of the same interval were equal for a regular stepwise calculation (see Section 1.3 for details). Because more than half of the 106 chronologies ended at or after AD 1999, we used the Regularized Expectation Maximization (RegEM) [35] method to extend the missing data. Eventually, all of the 106 chronologies covered a common period of time from AD 1953 to AD 1999. The period from AD 1953 to AD 1999 was used as the calibration period because it also overlapped the common period of all 244 PDSI grid data; this period was also used for the verification test of the reconstructions.

\subsection{Reconstruction method}

The reconstruction procedure generally follows the methods described by Mann et al. [36], except for some simplifications. As suggested by Mann, both two fundamental hypotheses (linear relationships between tree-ring chronologies and PDSI data, and the applicability of leading drought variation patterns derived from modern PDSI data for the past four centuries) are proved to be tenable in our study regions [37]. The reconstruction procedures include several steps, including (1) decomposition of modern (from AD 1953 to AD 1999) monthly averaged (from June to August) PDSI grid data into several principal patterns and their evolutionary series by means of conventional Principal Component Analysis (PCA), (2) calibration of each selected PDSI principal time series against the proxy network during the overlapped period from AD 1953 to AD 1999, (3) PDSI reconstruction in each year during the pre-1953 period using relationships from calculations in the calibration, and (4) cross-validation of the reconstructed PDSI against raw grid data (i.e. verification). During the reconstruction procedure, all of the instrumental PDSI grid data and chronologies spanned the common period from AD 1953 to AD 1999; thus, we tested the reliability of the reconstructed PDSI using the raw PDSI from this period.

Specifically, from AD 1953 to AD 1999, the 244-point monthly mean PDSI grid data from June to August were decomposed by means of PCA to generate several spatial patterns (derived from empirical orthogonal functions, EOFs) and their corresponding temporal scores (principal components, PCs). Since the first 20 pairs of EOFs and PCs accounted for the majority $(87.05 \%)$ of the total resolved variance, they could represent temporal and spatial variations in PDSI for the entire region. Therefore, from the first 20 pairs, we selected a few PCs that were statistically significantly correlated with each chronology and eventually used eight PCs (No. 1 to No. 8) and their corresponding EOFs in the reconstruction. We established a relationship matrix $\boldsymbol{W}(8,106)$ between the eight PCs matrix $\boldsymbol{U}(47,8)$ and the scattered tree ring-width sequences $\boldsymbol{P}(47,106)$ in the overlapped time span from AD 1953 to AD $1999\left(T_{1}=\right.$ $47)$, which could be expressed as an over-determined equations $\boldsymbol{U}(47,8) \boldsymbol{W}(8,106)=\boldsymbol{P}(47,106)$. Then, the relationship matrix $\boldsymbol{W}(8,106)$ served as the bridge from the tree-ring series to reconstructed PCs (RPCs) in each year before AD 1952, and the magnitude of the matrix $\boldsymbol{W}\left(8, N_{i}\right)$ decreased in each time interval $\left(T_{i}\right)$ as time went back because the tree-ring sample size $\left(N_{i}\right)$ decreased from $106\left(N_{2}\right)$ in the second interval from $\mathrm{AD} 1867$ to $\mathrm{AD} 1952\left(T_{2}\right)$ to 43 $\left(N_{7}\right)$ in the final interval from AD 1601 to $\mathrm{AD} 1650\left(T_{7}\right)$ (see Supplementary Material Table S3 for details of $T_{i}$ and $N_{i}$ ). These calculations could be expressed as another overdetermined equations $\hat{\boldsymbol{U}}\left(T_{i}, 8\right) \boldsymbol{W}\left(8, N_{i}\right)=\boldsymbol{P}\left(T_{i}, N_{i}\right)$. In the process of solving seven sets of over-determined equations, we used singular value decomposition to evaluate the leastsquares solutions. Although all sets of equations had the same number of unknowns, the number of equations in each set (i.e. each time span) lessened as the number of available chronologies decreased, which would lead to different amplitudes of change among each reconstructed PC $\hat{U}\left(T_{i}, 8\right)$ as well as the original PC $\boldsymbol{U}(47,8)$. Thus, we scaled $\hat{\boldsymbol{U}}\left(T_{i}\right.$, 8) with the ratio of standard deviations for the original PC and for RPCs in each time span so that they had an identical range of change amplitudes. These calculations worked well as long as the number of equations was larger than the number of unknowns, which was always realized in every time span as suggested by Mann et al. [36]. Finally, the PDSI values of 244 grids were reconstructed in every year from AD 1601 to AD 1952 by linearly combining the eight EOFs 
and RPCs.

In addition to reconstructing the PDSI in each year before AD 1953, we also recalculated the PDSI in each year from AD 1953 to AD 1999 so that we could compare original and recalculated PDSI values. Here, we computed resolved variance for each grid to estimate the homogeneity between actual and reconstructed PDSI values [36]. The results showed that during the period from AD 1953 to AD 1999, 238 of the 244 grids passed the test on at least a $99 \%$ significance level, and the other six grids passed the test on at least a 95\% significance level (Figure 3), which suggests high reliability of the reconstructions. Currently, based on the evidence of tree-ring chronologies, Cook et al. [23] used the point-to-point method to reconstruct yearly drought patterns of Asian monsoon regions over the past millennium; by comparison, our tree-ring dataset not only includes chronologies similar to those reported by Cook et al. [23] in the overlapped study area but also contains 20 chronologies sampled from northeastern China and North China, which makes our reconstruction more representative in the dryness and wetness of the arid, semiarid, and semihumid East Asia.

\section{Results and discussion}

\subsection{The principal components analysis}

The process of PCA enables us to decompose a two-dimensional dataset into a range of leading spatial patterns and their corresponding time series, which is an approach to reducing the dimension of the original data and is widely applied in meteorological research. Here, we decomposed the regular instrumental PDSI dataset to generate the principal spatial patterns (or EOFs) and the principal components (PCs). Both of the first two eigenvectors account for high fractions of variations $(20.74 \%$ and $13.29 \%$ of the total variance, respectively); thus, these two pairs of EOFs and PCs could be used to represent the dominant spatiotemporal variations in the arid and semiarid East Asia (Figure 4). By combining the first eigenvector and its time series, we found that the Qinghai-Tibetan Plateau and parts of higher latitudes showed opposite trends compared to the other regions. The former regions transferred from wetness to dryness in AD 1964 (having passed the Mann-Kendall test at a 95\% significance level), which was also recorded in other literature [38], whereas the latter regions transferred from dryness to wetness. The second eigenvector showed opposite trends in change between two sides of the meridional line around $105^{\circ} \mathrm{E}$. The western side includes eastern central Asia and the Xinjiang regions as well as the western part of the Hexi Corridor, and the eastern side includes most of Mongolia, North China, and northeastern China. This mode is probably correlated with the fact that the eastern area is under influence of the East Asia summer monsoon, whereas the western area is influenced by the westerly winds [39]. PC No. 2 suggested that the western area had a significant moistening trend after AD 1980 (having passed the MannKendall test at a 95\% significance level) and that the eastern area had a severe drying trend at the same time; this information was also reported and analyzed in other literature [40,41].

\subsection{Annual spatial patterns and history of drought}

By calculating the linear combinations of selected principal spatial patterns and their reconstructed PCs, we obtained the spatial pattern of PDSI in each year over the past 400 years, which helped to depict the spatiotemporal evolution of dryness and wetness in the arid, semiarid, and semihumid East Asia. In particular, three well-known severe drought events of the past four centuries, which occurred in the late Ming Dynasty (AD 1625 to AD 1644), AD 1876 to AD 1878, and 1920 s to 1940 s, were all identified in our reconstructed results.

During the period from the 1630 s to the 1640 s, severe

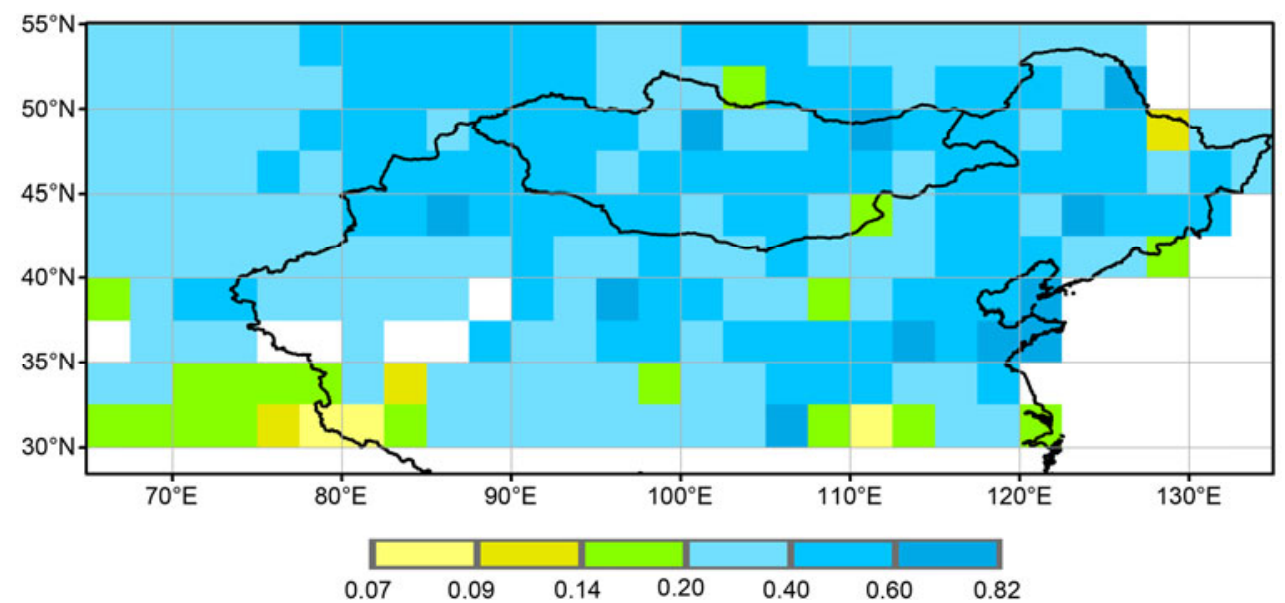

Figure 3 Resolved variance $\left(r^{2}\right)$ of reconstructed PDSI values to original PDSI values during the period from AD 1953 to AD 1999 ; colors denote values significant at the $95 \%$ (yellow), $97.5 \%$ (yellowish green), $99.5 \%$ (green), and $99.9 \%$ (blue) levels. 

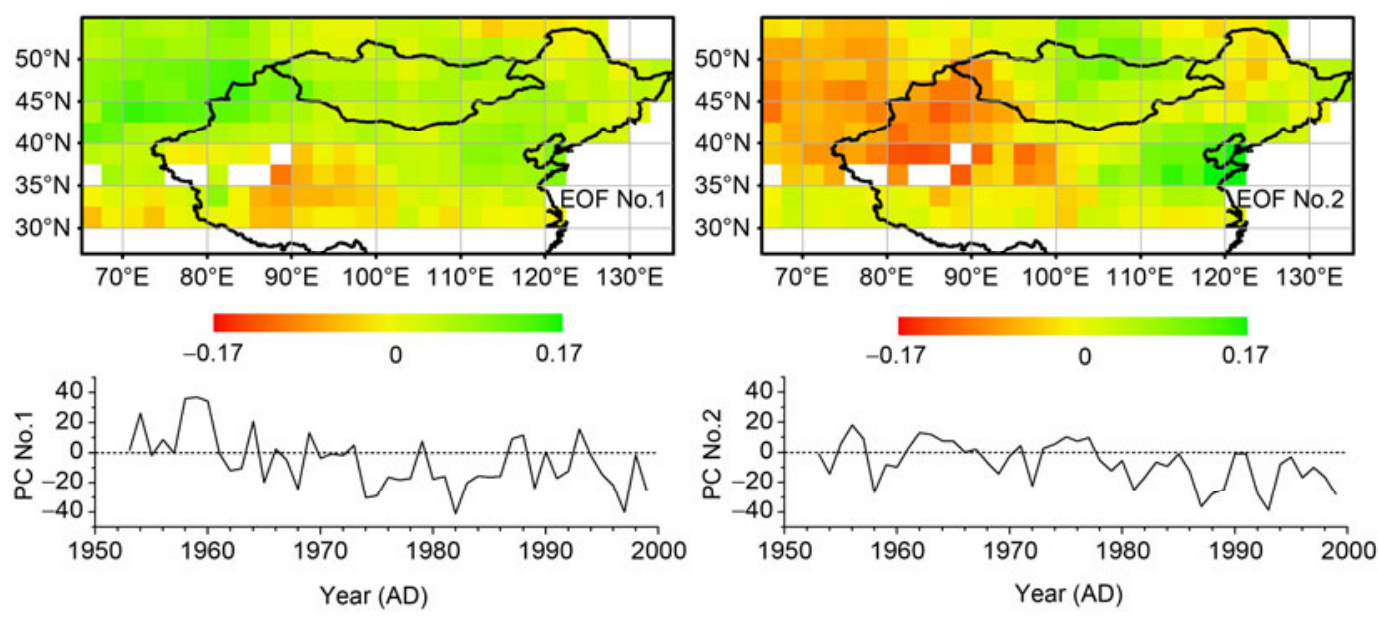

Figure 4 EOFs (upper) for the first two eigenvectors and their corresponding PCs (lower) of the PDSI in arid, semiarid, and semihumid regions of East Asia during the period from AD 1953 to AD 1999.

drought events occurred in North China. These successive years of droughts $[23,42,43]$ caused a large-scale famine $[44,45]$, which was believed to be one of the primary contributors to the collapse and eventual demise of the Ming Dynasty [46]. From our reconstructions, we also found that North China, especially the Hebei Province and its surrounding area, suffered intensive droughts from $\mathrm{AD} 1638$ to AD 1643 (Figure 5). Additionally, from AD 1876 to AD1878, most of northern China, especially Shaanxi, Shanxi, and Henan provinces [18], underwent serious droughts because of the strongest El Niño events of past 150 years [47]. When El Niño event occurred, the negative anomaly of sea surface temperature (SST) in west Pacific made the subtropical high move southward, and the consequent southward rain belt may result in occurrences of drought in the Yellow River drainage and other regions of northern China [11,48,49]. The drought event created sharp reductions in agricultural yields and caused a surge in the death toll [50,51]. Our reconstruction results also revealed that severe drought events occurred in most parts of northern China during the period from $\mathrm{AD} 1876$ to 1878 (Figure 6).

In addition, the great drought that occurred during the 1920s and 1940s over most of northern China and Mongolia continued for about 20 years and was regarded as one of the
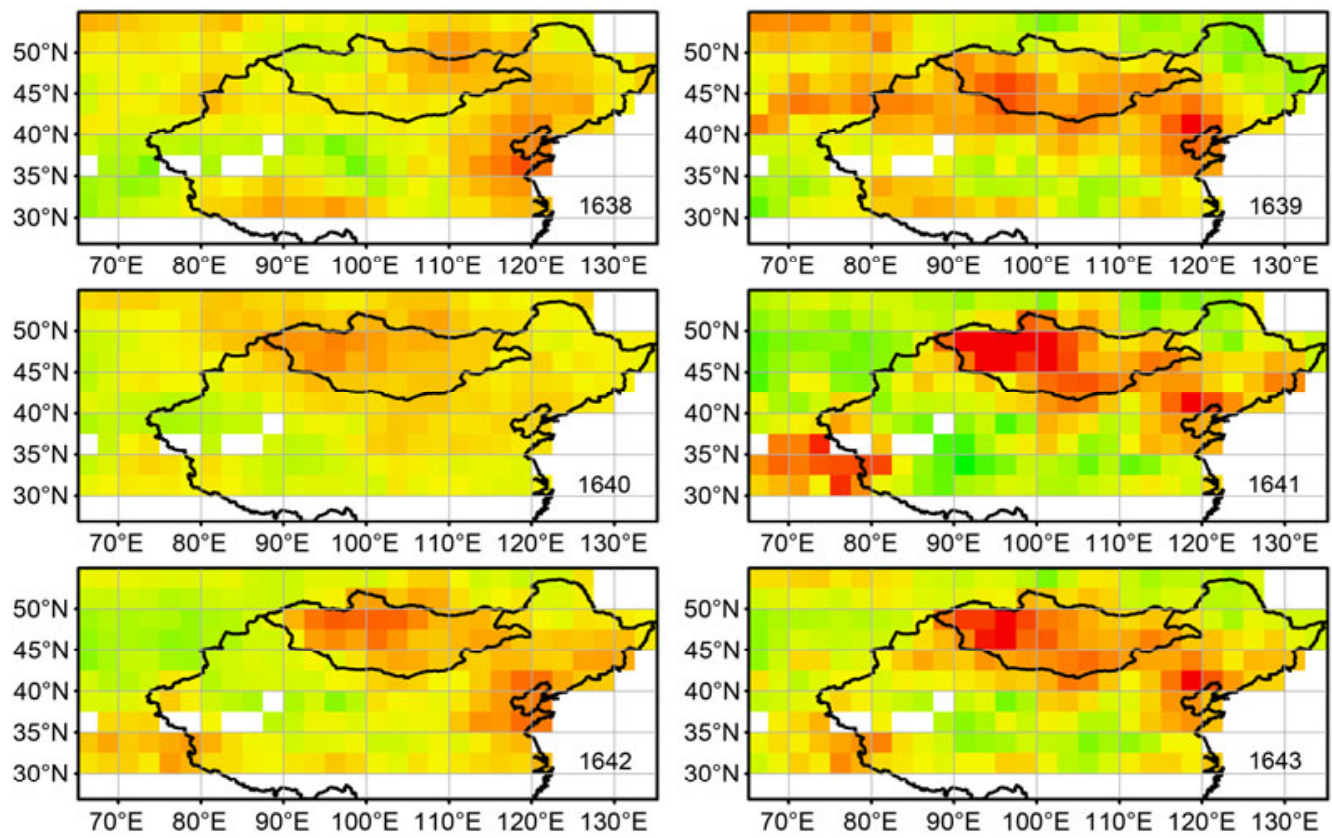

$-7$

0

Figure 5 Reconstructed PDSI patterns in the years during the late Ming Dynasty (only reconstruction of some representative years are shown due to limited space). 

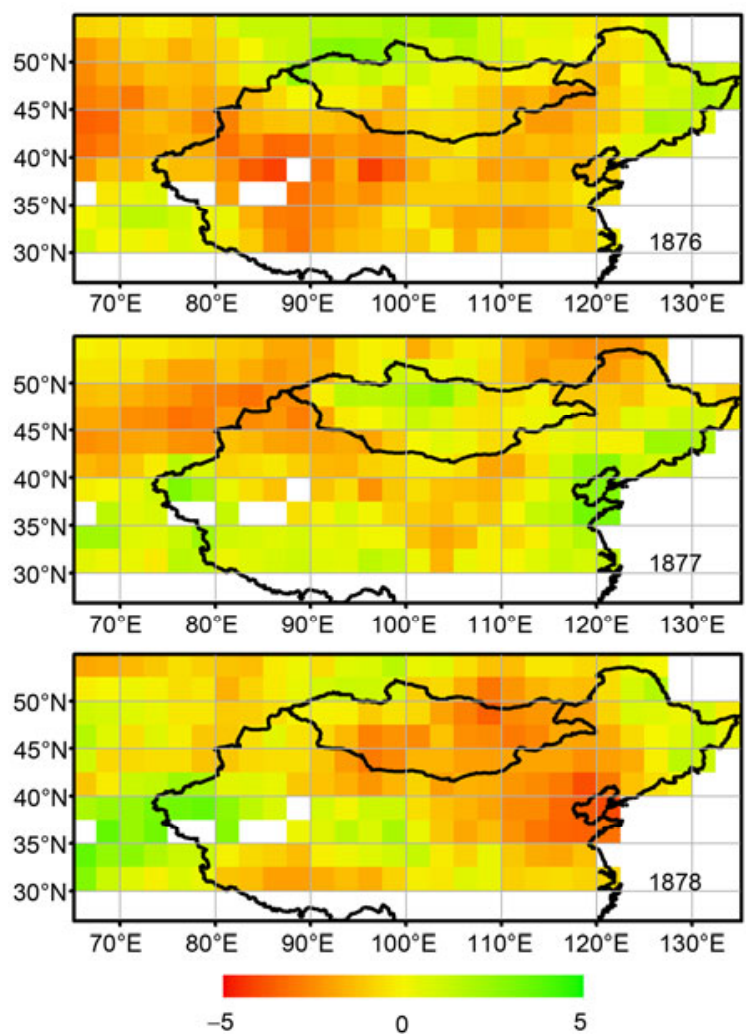

Figure 6 Reconstructed PDSI patterns in each year from AD 1876 to AD 1878.

most severe natural hazards over the past 200 years [52,53]. This catastrophic drought caused widespread crop failures [53] and millions of deaths during the famines that followed
[54]. Our reconstruction results also showed that most parts of northern China and Mongolia suffered from successive serious droughts from 1928 to AD 1930 and from AD 1937 to AD 1943 (Figure 7), which was highly consistent with historical records. Specifically, the catastrophic drought in Henan Province that occurred after AD 1941, which reached its peak in AD 1942, spread throughout the entire province. This severe drought was accompanied by the locust plague in the next year (AD 1943) [55], which altogether had a destructive impact on local lives and caused tens of thousands of people to die of starvation.

Although there are some uncertainties in our reconstructions due to biases during the data integration process because of the unevenly distributed tree-ring sites and rapid reduction in sample size going back in time, these historical, well-known drought events could be strong evidence to support our reconstruction results.

\subsection{Historical drought events and possible contributors}

We calculated the area average of time series at all grids to represent the holistic PDSI series of the arid, semiarid, and semihumid areas of East Asia over the past 400 years (Figure 8). Although all of the grids spanned several different latitudes, they were still assigned with equal weight because the area differences in the small range of latitudes are not so obvious that the grid area would be affected. The total reconstructed PDSI sequences were smoothed using a 10-year low-pass filter and are shown in Figure 8. The results showed that the arid, semiarid, and semihumid East Asia experienced multiple dryness and wetness fluctuations during the
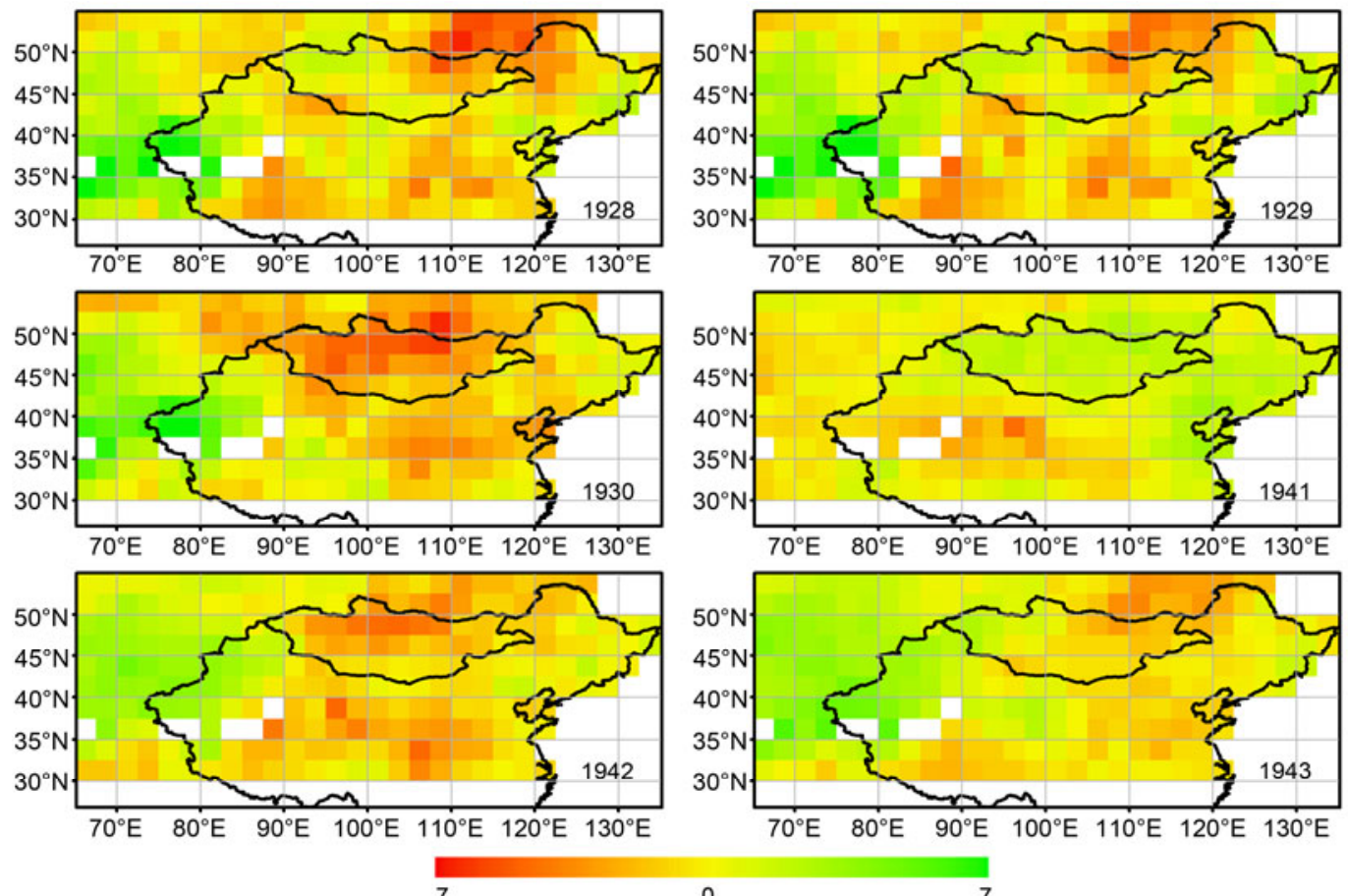

Figure 7 Reconstructed PDSI in the years from AD 1920s to AD 1940s (only reconstruction of some representative years are shown due to limited space). 


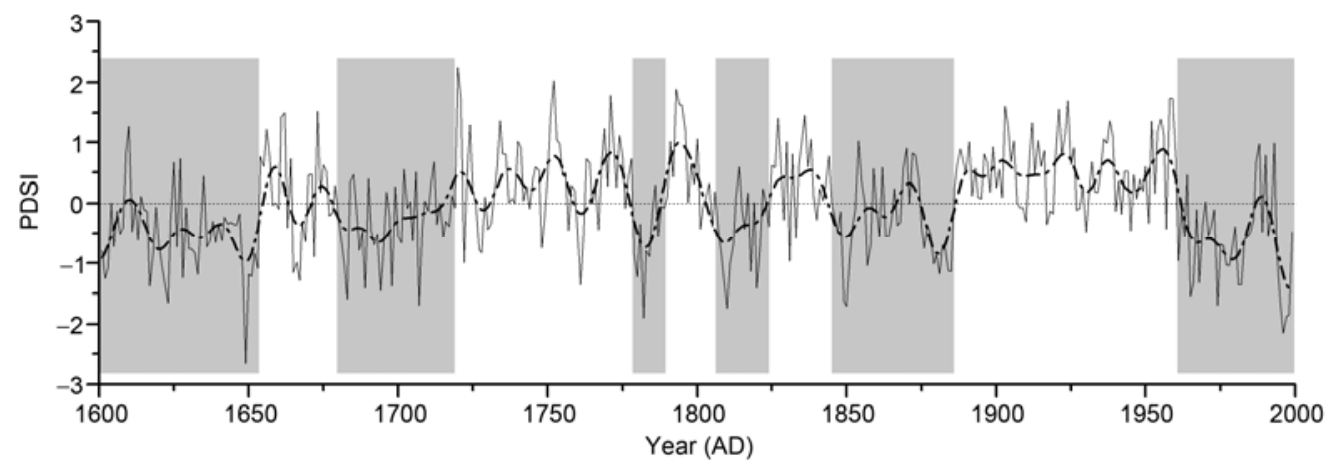

Figure 8 Variations in total reconstructed PDSI (solid line) and its 10-year smoothed sequence (dashed line) in arid, semiarid, and semihumid East Asia over the past four centuries. Key phases of drought are shown in gray shades.

period from $\mathrm{AD} 1601$ to $\mathrm{AD}$ 1999: these regions suffered severe droughts from AD1601 to AD1652, AD 1680 to AD 1718, AD 1779 to AD 1791, AD 1807 to AD 1824, AD 1846 to AD 1885, and AD 1961 to AD 1999 and witnessed relatively humid climate in the periods between droughts.

Since our study area covers a large extent of land with multiple climate modes, the influences of temperature and summer monsoon on dryness are complicated and may vary among the different regions, especially between the western non-monsoon regions and the eastern monsoon regions, where the climate and environment are very different. Therefore, variations in forcing factors would have more complicated influences on trends in PDSI over regions with and without the impact of the East Asia summer monsoon, we thus divided the study region at the meridian at $105^{\circ} \mathrm{E}$ (as suggested from EOF No. 2) and calculated area averages on both sides of the dividing line (Figure 9(a) and (b)).

Although several external forcing factors, such as solar irradiance variations, volcanic explosions, and changes in atmospheric greenhouse gases, could have fundamental influences on variations in dryness and wetness [56-58], temperature and Asian summer monsoon would have more straightforward influences $[23,59,60]$. The temperature and summer monsoon history for the arid, semiarid, and semihumid regions of East Asia has been reconstructed by other scientists $[23,42,61]$. Here, we used reconstructed Northern Hemisphere temperatures based on the worldwide tree-ring series by Mann et al. [36] and $\delta^{18} \mathrm{O}$ sequence from Wanxiang Cave to indicate Asian summer monsoon [42] (Figure 9(c) and (d)), and a running correlation test with a window width of 100 years was used to check the influences of these factors on droughts in western and eastern areas. The temperature series were derived by an independent tree-ring network in the present study; thus, the reliability of the test results would not change. The running window contained 100 years. The central year started at AD 1650, which calculated the correlation during the period from AD 1601 to AD 1700. Then, the central year moved to AD 1651, which calculated the correlation during the period from AD 1602 to AD 1701. Calculations continued until the central year ended at AD 1931, which calculated the period from AD 1881 to AD 1980. Finally, time series of the correlation coefficients between temperature and PDSI in both western and eastern areas were obtained (Figure 9 (e)).

Figure 9(a) and (b) shows differences between the historical PDSI in the western and eastern areas over the past four centuries. Divergences exist between the correlation of reconstructed PDSI with temperature and with summer monsoon in both areas (Figure 9(e)): PDSI in the western area had a higher positive correlation with temperature but a lower relationship with monsoon (correlation coefficients fluctuated around zero), while PDSI in the eastern area had a close correlation with Asian summer monsoon but little correlation with temperature (correlation coefficients fluctuated around zero). These differences may be related to distinct regional climate characteristics. In the western area, Asian summer monsoon had little influence on dryness and wetness because this area lies beyond the scope of the Asian summer monsoon; by comparison, a rise in temperature and accompanying increase in precipitation [62] are the main reasons for variations in regional droughts and floods. As a result, PDSI in this area had a relatively higher positive correlation with temperature. In contrast, in the eastern area, although an increase in temperature would lead to relative dryness because of massive water loss accompanied by evaporation, since the eastern area falls within the scope of the summer monsoon, the strength of the summer monsoon and its associated precipitation would play a dominant role in regional warm-season dryness and wetness [63]. Therefore, the PDSI in the eastern area had a higher positive correlation with the summer monsoon. In addition, over around 200 years (1670s to 1880 s), both temperature and summer monsoon have a significant correlation $(P<0.05)$ with PDSI in the western and eastern areas, respectively. During the time before and after this 200-year period, both correlation coefficients failed to pass the significance test $(P<0.05)$ at the same time, probably because PDSI during these two periods are under the influences of special climate conditions. During the period from the 1600 s to 1670 s, being recognized as the Little Ice Age Maximum [64,65], the weakened 


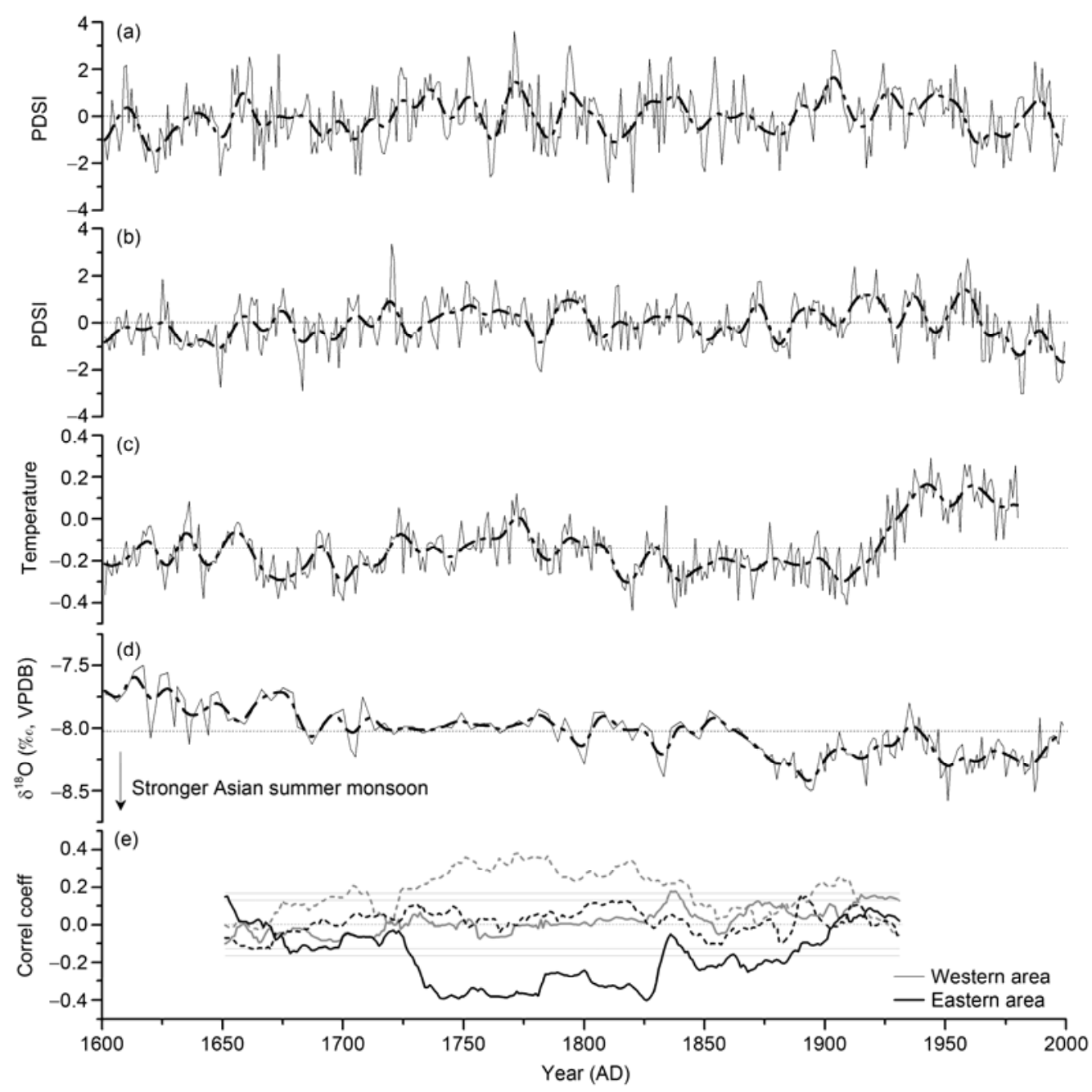

Figure 9 Variations in the average reconstructed PDSI in the (a) western area and (b) eastern area; (c) reconstructed Northern Hemisphere temperatures [36]; (d) $\delta^{18} \mathrm{O}$ of Wanxiang Cave [42]; and (e) 100-year running correlation coefficients (Correl coeff) between reconstructed PDSI and temperature series (dashed lines) and $\delta^{18} \mathrm{O}$ sequence (solid lines) in both areas over the past four centuries. Two pairs of light gray lines suggest thresholds at 0.1 and 0.05 significance levels.

Asia summer monsoon and low mean temperature (Figure 9(c) and (d)) may have less effective impacts on PDSI in western and eastern areas, respectively. During the latter period from the 1880s to 2000s, with the end of the Little Ice Age and the increased greenhouse effect, temperature had increased greatly, triggering enhancement of evaporation with massive moisture loss [66]. As a result, in the western areas, increased temperature had both positive and negative impacts on variations in PDSI, and thus there were no significant correlations between temperature and PDSI during this period; in the eastern areas, although the strengthened summer monsoon accompanying increased precipitation promoted wetting trend, rises in temperature with enhanced evaporation acted reversely to dryness and wetness, therefore, insignificant correlations were found between Asia summer monsoon and PDSI in this period. However, we list here are only conjectural explanations, and further investigative studies are still needed.

\section{Conclusion}

(1) The PCA shows the existence of two opposite changes in drought patterns in the arid, semiarid, and semihumid East Asia, including a reversed-phase change between the Qinghai-Tibetan Plateau and the other regions and between western nonmonsoon regions and eastern monsoon regions.

(2) The reconstruction results show the spatiotemporal variations of drought over the past 400 years and the extent of three notable drought event. For example, during the late Ming Dynasty, continued severe droughts occurred in North China; drought events from 1876 to 1878 took place mainly in North China and northeastern China; and the disastrous drought of the 1920s to 1940s spread throughout northern China and the Mongolian Plateau.

(3) Our results also suggest that the study regions experienced dryness from $\mathrm{AD} 1601$ to $\mathrm{AD} 1652, \mathrm{AD} 1680$ to $\mathrm{AD}$ 1718, AD 1779 to AD 1791, AD 1807 to AD 1824, AD 
1846 to AD 1885, and AD 1961 to AD 1999. Temperature and summer monsoon precipitation are the main contributors to those variations; in the western area, temperature had a close relationship with PDSI, but in the eastern area, summer monsoon precipitation may play a dominant role in regional dryness and wetness.

Although previous studies reconstructed high-resolution temporal and spatial variations in droughts over the Asian summer monsoon region, our reconstruction may help provide valuable information on historical drought in northern China because our tree-ring database consists of many chronologies sampled from northeastern China and North China, which are absent in previous literature. Our reconstruction results show that under modern global change, most of arid, semiarid, and semi-humid East Asia has experienced drying trend since the $1960 \mathrm{~s}$, which is consistent with the increased evaporation under the global greenhouse gas- induced warming.

This work was supported by the National Natural Science Foundation of China (41225001) and the National Key Project of Scientific and Technical Supporting Program (2012BAC19B09).

1 Sheffield J, Wood E F, Roderick M L. Little change in global drought over the past 60 years. Nature, 2012, 491: 435-438

2 Easterling D R, Meehl G A, Parmesan C, et al. Climate extremes: Observations, modeling, and impacts. Science, 2000, 289: 2068-2074

3 Gong D, Han H. Extreme climate events in Northern China over the last 50 years (in Chinese). Acta Geogr Sin, 2004, 59: 230-238

4 Breshears D D, Cobb N S, Rich P M, et al. Regional vegetation die-off in response to global-change-type drought. Proc Natl Acad Sci USA, 2005, 102: 15144-15148

5 Briffa K R, van der Schrier G, Jones P D. Wet and dry summers in Europe since 1750: Evidence of increasing drought. Int J Climatol, 2009, 29: 1894-1905

6 Cai W, Cowan T, Briggs P, et al. Temperature depletes soil moisture and exacerbates severe drought conditions across southeast Australia. Geophys Res Lett, 2009, 36: L21709

7 Huang G, Liu Y, Huang R. The interannual variability of summer rainfall in the arid and semiarid regions of northern China and its association with the Northern Hemisphere circumglobal teleconnection. Adv Atmos Sci, 2011, 28: 257-268

8 Shen C, Wang W, Hao Z, et al. Exceptional drought events over eastern China during the last five centuries. Clim Change, 2007, 85: 453-471

9 Wang X M, Chen F H, Hasi E, et al. Desertification in China: An assessment. Earth-Sci Rev, 2008, 88: 188-206

10 Wang X M, Chen F H, Zhang J W, et al. Climate, desertification, and the rise and collapse of China's historical dynasties. Hum Ecol, 2010, 38: $157-172$

11 Tao F, Yokozawa M, Zhang Z, et al. Variability in climatology and agricultural production in China in association with the East Asian summer monsoon and El Niño Southern Oscillation. Clim Res, 2004, 28: $23-30$

12 Prospero J M, Lamb P J. African droughts and dust transport to the Caribbean: Climate change implications. Science, 2003, 203: 1024 1028

13 Qian W, Quan L, Shao S. Variations of the dust storm in China and its climatic control. J Clim, 2002, 15: 1216-1229

14 Wang X, Dong Z, Zhang J, et al. Modern dust storms in China: An overview. J Arid Environ, 2004, 58: 559-574

15 Reynolds J F, Smith D M S, Lambin E F, et al. Global desertification:
Building a science for dryland development. Science, 2007, 316: $847-851$

16 Davi N K, Jacoby G C, D'Arrigo R D, et al. A tree-ring-based drought index reconstruction for far-western Mongolia: 1565-2004. Int J Climatol, 2009, 29: 1508-1514

17 Song J. Reconstruction of the Southern Oscillation from dryness/wetness in China for the last 500 years. Int J Climatol, 1998, 18: 1345-1355

18 Song J. Changes in dryness/wetness in China during the last 529 years. Int J Climatol, 2000, 20: 1003-1015

19 Chen F, Chen J, Holmes J, et al. Moisture changes over the last millennium in arid central Asia: A review synthesis and comparison with monsoon region. Quat Sci Rev, 2010, 29: 1055-1068

20 Fang K, Davi N, Gou X, et al. Spatial drought reconstructions for central High Asia based on tree rings. Clim Dyn, 2010, 35: 941-951

21 Liang E, Shao X, Liu H, et al. Tree-ring based PDSI reconstruction since AD 1842 in the Otindag Sand Land, east Inner Mongolia. Chin Sci Bull, 2007, 52: 2715-2721

22 Tian Q, Gou X, Zhang Y, et al. Tree-ring based drought reconstruction (A.D. 1855-2001) for the Qilian Mountain, Northwestern China. Tree-ring Res, 2007, 63: 27-36

23 Cook E R, Anchukaitis K J, Buckley B M, et al. Asian monsoon failure and megadrought during the last millennium. Science, 2010, 328: 486-489

24 Liu W, Gou X, Yang M, et al. Drought reconstruction in the Qilian Mountain over the last two centuries and its implications for largescale moisture patterns. Adv Atmos Sci, 2007, 83: 133-149

25 Chen F, Yu Z, Yang M, et al. Holocene moisture evolution in arid central Asia and its out-of-phase relationship with Asian monsoon history. Quat Sci Rev, 2008, 27: 351-364

26 Jiang J, Zhang D, Fraedrich K. Historic climate variability of wetness in east China (960-1992): A wavelet analysis. Int J Climatol, 1997, 17: 969-981

27 Ge Q, Zheng J, Fang X, et al. Winter half-year temperature reconstruction for the middle and lower reaches of the Yellow River and Yangtze River, China, during the past 2000 years. Holocene, 2003, 13: 933-940

28 Qian W, Hu Q, Zhu Y, et al. Centennial-scale dry-wet variations in East Asia. Clim Dyn, 2003, 21: 77-89

29 Davi N K, Jacoby G C, Curtis A E, et al. Extension of drought records for Central Asia using tree rings: West-Central Mongolia. J Clim, 2006, 19: 288-299

30 Chen Z, Zhang X, Cui M, et al. Tree-ring based precipitation reconstruction for the forest-steppe. Glob Planet Change, 2012, 86-87: 45-56

31 Palmer W C. Meteorological drought, Weather Bureau Research Paper 45. Washington DC: U.S. Department of Commerce, 1965

32 Alley W M. The Palmer Drought Severity Index: Limitations and assumptions. J Clim Appl Meteorol, 1984, 23: 1100-1109

33 Dai A, Trenberth K E, Qian T. A global dataset of Palmer Drought Severity Index for 1870-2002: Relationship with soil moisture and effects of surface warming. J Hydrometeorol, 2004, 5: 1117-1130

34 Guttman N B, Wallis J R, Hosking R M. Spatial comparability of the Palmer Drought Severity Index. J Am Water Resour As, 1992, 28: 1111-1119

35 Schneider T. Analysis of incomplete climate data: Estimation of mean values and covariance matrices and imputation of missing values. J Clim, 2001, 14: 853-871

36 Mann M E, Bradley R S, Hughes M K. Global-scale temperature patterns and climate forcing over the past six centuries. Nature, 1998, 392: 779-787

37 Li J, Chen F, Cook E R, et al. Drought reconstruction for north Central China from tree rings: The value of the Palmer Drought Severity Index. Int J Climatol, 2007, 27: 903-909

38 Mao F, Tang S, Sun H, et al. A study of dynamic change of dry and wet climate regions in the Tibetan Plateau over the last 46 years (in Chinese). Chin J Atm Sci, 2008, 32: 499-507

39 Qian W, Qin A. Precipitation division and climate shift in China from 1960 to 2000. Theor Appl Climatol, 2008, 93: 1-17 
40 Zou X, Zhai P, Zhang Q. Variations in droughts over China: 19512003. Geophys Res Lett, 2005, 32: L04707

41 Shi Y, Shen Y, Kang E, et al. Recent and future climate change in northwest China. Clim Change, 2007, 80: 379-393

42 Zhang P Z, Cheng H, Edwards R L, et al. A test of climate, sun, and culture relationships from an 1810-year Chinese cave record. Science, 2008, 322: 940-942

43 Chinese Academy of Meteorological Sciences. Yearly Charts of Dryness/Wetness in China for the Last 500-Year Period (in Chinese). Beijing: Cartographic Publishing House, 1981

44 Fan W. Encyclopedia of Chinese History (in Chinese). Vol. 3. Beijing: People's Press, 1965

45 Hsu K J. Sun, climate, hunger, and mass migration (in Chinese). Sci China Ser D-Earth Sci, 1998, 41: 449-472

46 Cai M B. Encyclopedia of Chinese History (in Chinese). Vol. 8-10. Beijing: People's Press, 1965

47 Davis M. Late Victorian Holocausts: El Niño Famine sand the Making of the Third World. London: Verso, 2001

48 Huang $\mathrm{R}, \mathrm{Wu}$ Y. The influence of ENSO on the summer climate change in China and its mechanism. Adv Atmos Sci, 1989, 6: 21-32

49 Lau K M, Weng H. Coherent modes of global SST and summer rainfall over China: An assessment of regional impacts of the 1997-98 El Niño. J Clim, 2001, 14: 1294-1308

50 Zhang D, Liang Y. A long lasting and extensive drought event over China during 1876-1878 (in Chinese). Adv Clim Change Res, 2010, 6: 106-112

51 Hao Z X, Zheng J Y, Wu G F, et al. 1876-1878 severe drought in North China: Facts, impacts and climatic background. Chin Sci Bull, 2010, 55: 3001-3007

$52 \mathrm{Xu}$ G C. Climate Change in Arid and Semiarid Regions of China (in Chinese). Beijing: China Meteorological Press, 1997. 101

53 Liang E, Liu X, Yuan Y, et al. The 1920s drought reconstructed by tree rings and historical documents in the semi-arid and arid areas of northern China. Clim Change, 2006, 79: 403-432
54 Fang K, Gou X, Chen F, et al. Tree-ring based drought reconstruction for the Guiqing Mountain (China): Linkages to the Indian and Pacific Oceans. Int J Climatol, 2009, 30: 1137-1145

55 Cui M. A brief examination of the drought, wind, and locust disaster during the period 1942-1943 in Henan Province (in Chinese). J Catastrophol, 1994, 9: 74-77

56 Stuiver M. Solar variability and climatic change during the current millennium. Nature, 1980, 286: 868-871

57 Hansen J E, Lacis A A. Sun and dust versus greenhouse gases: An assessment of their relative roles in global climate change. Nature, 1990, 346: 713-719

58 Briffa K R, Jones P D, Schweingruber F H, et al. Influence of volcanic eruptions on Northern Hemisphere summer temperature over the past 600 years. Nature, 1998, 393: 450-455

59 Yang S, Lau K M. Influences of sea surface temperature and ground wetness on Asian summer monsoon. J Clim, 1998, 11: 3230-3246

60 Yang S, Ding Z. Advance-retreat history of the East Asian summer monsoon rainfall belt over northern China during the last two glacial-interglacial cycles. Earth Planet Sci Lett, 2008, 274: 499-510

61 Tan M, Liu T, Hou J, et al. Cyclic rapid warming on centennial-scale revealed by a 2650-year stalagmite record of warm season temperature. Geophys Res Lett, 2003, 30: 1617-1620

62 Gao X, Zhao Z, Ding Y, et al. Climate change due to greenhouse effects in China as simulated by a Regional Climate Model. Adv Atmos Sci, 2001, 18: 1224-1230

63 Ding Y, Chan J C L. The East Asian summer monsoon. Meteorol Atmos Phys, 2005, 89: 117-142

64 Wang S, Liu J, Zhou J. The climate of Little Ice Age Maximum in China. J Lake Sci, 2003, 15: 369-370

65 Wang S, Wen X, Luo Y, et al. Reconstruction of temperature series in China during the last millennium. Chin Sci Bull, 2007, 52: 958964

66 Ma Z G, Fu C B. Some evidence of drying trend over north China from 1951 to 2004. Chin Sci Bull, 2006, 51: 2913-2925

Open Access This article is distributed under the terms of the Creative Commons Attribution License which permits any use, distribution, and reproduction in any medium, provided the original author(s) and source are credited.

\section{Supporting Information}

Table S1 Descriptions of tree-ring chronologies

Table S2 Correlation coefficients between each tree-ring chronology and its nearest PDSI

Table S3 Details of each of seven reconstruction intervals

The supporting information is available online at csb.scichina.com and www.springerlink.com. The supporting materials are published as submitted, without typesetting or editing. The responsibility for scientific accuracy and content remains entirely with the authors. 